\title{
Air Quality Monitoring System in Thingspeak-Based Applications Using Internet of Things (IOT)
}

\author{
SAMUEL KRISTIYANA, ALDI RINALDI \\ Department of Electrical Engineering \\ Institute of Science \& Technology AKPRIND \\ Kalisahak st. 28, Komplek Balapan, Yogyakarta \\ INDONESIA
}

\begin{abstract}
The monitoring system in this study is a system created to find out data about temperature, humidity, and air quality in a room. This research develops a monitoring system that uses the internet so that the monitoring range becomes wider. By utilizing the Internet of Things (IoT) technology using the thingspeak application integrated with the NodeMCU module ESP8266 features an LM35 temperature sensor that functions as a temperature detector, a DHT11 sensor as a humidity sensor, and an MQ-135 sensor as an air quality detector. These sensors send input signals to the NodeMCU ESP8266 module for processing. The wifi module contained in the NodeMCU ESP8266 module sends the value read by the sensor to the IoT Thingspeak platform which records logging data in graphical form. This system has the potential to be used as an indoor air quality monitoring system to raise awareness about the importance of healthy air quality..
\end{abstract}

Keywords: Internet of Things, Monitoring, Thingspeak, Air Quality, NodeMCU ESP8266

Received: October 16, 2019. Revised: March 2, 2020. Accepted: March 17, 2020. Published: March 31, 2020.

\section{Introduction}

Internet of Things canbe viewed ,as a global infrastructure for the information society,enabling advanced services by interconnecting (physical and virtual)things based on, existing and evolving, interoperable information andcommunication technologies" [1][6]. Most people still consider air pollution to occur only outdoors and usually comes from vehicle fumes, dust, to factory exhaust fumes. In fact, the air in the house that has been inhaled is also vulnerable to pollutant particles that can interfere with body health. A simple example is when you wake up in the morning and feel the throat feels itchy so that you have to get rid of itching in the throat with a cough, even though you're not in a cough condition. That is an indication that the air quality in the room is bad. This will have a negative impact on future health. Moreover, occupying the room every day.

Humidity is the moisture contained in the air. If too much, it will be increasingly bad for health. According to Medicalogy, the ideal condition of humidity in the room is $45 \%$. If the humidity in the room is below $15 \%$ it is too dry, and the condition above $50 \%$ is too humid. Then the recommended conditions are in the range of $15 \%-50 \%$, and the most ideal is as previously stated at $45 \%$.

Chemicals that are in the content of floor cleaners like the ones we use everyday can also cause bad room conditions. Maybe it has smelled from the floor that has been mopped very fragrant, actually it is a chemical substance, but the product is mixed with a familiar fragrance in our nose in order to eliminate the true smell of these chemicals. But still it is a chemical that is harmful to health if we breathe it. So it is advisable to open the window so that the odor from these chemicals decreases.

Then from the air freshener, we certainly often use it to make the room fragrant so it is more pleasant to be inhaled. But in reality, room deodorizers contain a substance called dichlorobenzene which makes the person inhaling it reduce the function of the lungs up to $40 \%$. So to handle it, use a room deodorizer from essential oils made from natural plants.

The condition of the room filled with cigarette smoke makes the air quality in the room must also be very bad. Cigarette smoke contains toxic chemicals that can cause people who smoke and people who inhale cigarette smoke in addition to causing respiratory problems, inhaling cigarette smoke can also cause cancer. So if you want the room to avoid cigarette smoke, it is advisable not to smoke indoors and if you want to smoke it is better outside the room / outdoors.

The air coming from outside the room is also very potential to make the quality of the air in our room to be very bad. IQ Air-Air Visual notes that in 2018 Indonesia will be the most polluted country in Southeast Asia. Pollution caused by motor vehicle fumes, combustion fumes, and others. We certainly often open the air vents of the house in the hope that air from outside enters the house to be better. The fact is not, unless we live in a rural or residential 
area far from urban / factory areas / waste incineration areas.

A healthy environment is very influential on the physical health of living things. An important factor supporting a healthy environment is air quality that meets health standards. Air contains oxygen needed for life. But besides oxygen, there are other substances in the air such as carbon monoxide, carbon dioxide, formaldehyde, fungi, viruses, bacteria, dust and so on. Oxygen inside and outside the room can be contaminated with substances that are harmful to health. Within certain limits the levels of these substances can still be neutralized but if it exceeds normal limits it can interfere with health. The World Health Organization (WHO) states that hazardous substances originating from buildings, construction materials, equipment, combustion or heating processes can trigger health problems[3].

Increased human activity has triggered the problem of air pollution, so we need a solution to be able to minimize the effects that can interfere with health. Although at certain times humans can use the senses to estimate if the air in the surrounding environment is at normal levels and not polluted or vice versa, but for continuous monitoring, humans are limited by time and space. To conduct real-time monitoring and obtain data on temperature, humidity and air quality can be done by building a hardware connected to the monitoring system.

\subsection{Formulation of the problem}

The formulation of the problem in this research is how to develop a system that can record data about temperature, humidity and air quality in a room through IoT.

\section{Theoretical basis}

\subsection{Humidity}

Humidity of air is the amount of moisture present in the air. The water vapor content in the air varies depending on the temperature the higher the temperature, the more water vapor content. The air humidity gauge is a hygrometer. There are 2 types of air humidity as follows:

1. Absolute humidity (absolute) is a number that shows the amount of water vapor in grams in one cubic meter of air.

2. Relative humidity (nisbi), a number in percent which shows the ratio between the amount of water vapor actually contained in the air at a certain temperature and the maximum amount of water vapor that can be contained in the air.
Relative humidity is calculated using equation 1 :

$$
\mathrm{K}=\mathrm{T} / \mathrm{P} \times 100 \%
$$

Where:

$\mathrm{K}=$ relative humidity.

$\mathrm{T}=$ water vapor in the air at a certain temperature.

$\mathrm{P}=$ maximum moisture content capacity.

\subsection{NodeMCU ESP8266}

From previous research[5], the microcontroller in this system was changed using NodeMCU ESP8266

ESP8266 is a wifi module that functions as an additional microcontroller such as Arduino to connect directly with WIFI and make TCP / IP connections[7].

NodeMCU is an IoT platform that is open source. Consists of hardware in the form of System On Chip ESP8266 from ESP8266 made by Espressive System, as well as the firmware used, which uses the Lua scripting programming language. The term NodeMCU by default actually refers to the firmware used rather than the hardware development kit.

NodeMCU can be analogous to the ESP8266 arduino board. In the ESP8266 tutorial series embeddednesia once discussed how to program ESP8266 is a bit troublesome because it requires some wiring techniques and an additional USB to serial module to download the program. However, NodeMCU has ESP8266 package into a compact board with various features like a microcontroller + access capability to Wifi as well as a USB to serial communication chip. So to program it only requires the exact USB data cable extension that is used as a data cable and Android smartphone charging cable.

\subsection{DHT11 Sensor}

DHT11 is one sensor that can measure two environmental parameters at once, namely temperature and humidity (humidity). In this sensor there is an NTC type thermistor.

A resistive type humidity sensor and an 8-bit microcontroller that processes the two sensors and sends the results to the output pin with a singlewire bi-directional format (single cable bidirectional).

\subsection{MQ-135 Sensor}

The MQ-135 sensor is a gas sensor has low conductivity if it is on clean air. The conductivity of the sensor will rise along with the increase in gas concentration. For convert to gas density, this sensor requires an additional electrical circuit. The advantage of this sensor is having good sensitivity to harmful gases (Ammonia, Sulfide, Benzene) in 
various concentration, long active period and requires lower costs.

\subsection{Thingspeak}

Thingspeak is an IoT platform that can collect and store data in the cloud and develop IoT applications. Data from sensors can be sent to Thingspeak from Arduino, Raspberry Pi, BeagleBone Black, and other hardware. To be able to use the Thingspeak platform, users need to create an account and determine the channel on that account. The Thingspeak platform will provide an API key which is then regulated within the microcontoler program, so that it can perform the function of sending data from the sensor to Thingspeak.[9]. The main role of updating data continuously is done by Thingspeak, which has APIs for collecting data produced by sensors and APIs for reading that data from applications. The paper is divided into two parts. One part of the paper is where one has to program a thing to send data. And, the second part is where the other has to see the data. Thingspeak sits in the middle and makes it handy to do both. The paper uses easily accessible hardware to build a proof-of-concept IoT system to monitor air temperature, humidity, soil moisture, soil humidity etc. Further this can be modified with different sensors or actuators for building something for individual purposes. Thus a direct access to all the environmental parameters is given to the user after the above stated procedure is completed[11].

The Internet of Things(IoT) is a system of 'connected things'. The things generally comprise of an embedded operating system and an ability to communicate with the internet or with the neighboring things. One of the key elements of a generic IoT system that bridges the various 'things' is an IoT service. The real power of IoT is harnessed when the things connect to a 'service' either directly or via other 'things'. In such systems, the service plays the role of an invisible manager by providing capabilities ranging from simple data collection and monitoring to complex data analytics. ThingSpeak is a platform providing various services exclusively targeted for building IoT applications. It offers the capabilities of real-time data collection, visualizing the collected data in the form of charts, ability to create plugins and apps for collaborating with web services, social network and other APIs.

The core element of ThingSpeak is a 'ThingSpeak Channel'. A channel stores the data that we send to ThingSpeak and comprises of the below elements:
- 8 fields for storing data of any type - These can be used to store the data from a sensor or from an embedded device.

- 3 location fields - Can be used to store the latitude, longitude and the elevation. These are very useful for tracking a moving device.

- 1 status field - A short message to describe the data stored in the channel.

To use ThingSpeak, we need to sign up and create a channel. Once we have a channel, we can send the data to the channel using WriteAPIKey and allow ThingSpeak to process it and also retrieve the same[13].

\subsection{Internet of Things (IOT)}

Internet of Things refers to unique objects that can be identified and represented virtually into the structure of the Internet [10]

Internet of Things (IoT) is a concept / scenario where an object has the ability to transfer data through a network without requiring human-tohuman or human-computer interaction. "A Things" on the Internet of Things can be defined as a subject, for example a person with a heart implant monitor, a farm animal with a biochip transponder, a car that has a built-in sensor to warn the driver when tire pressure is low.

Internet of Things (IoT) is one of the hottest topics right now. However, its beginning is dated with the first usage of RFID in 2000. Since this time thanks to technological progress many obstacles have been passed. It allows the rapid rise of smart devices around us. The term IoT covers physical devices, that are empowered with technologies and sensors which allows them to get data from the real world, communicate with each other through the network and act according to an evaluation of gathered data [12].

IoT-related healthcare systems are based on the essential definition of IoT as ,,anetwork of devices that connect directly with each other to capture and share vital data througha secure service layer that connects to a central command and control server in thecloud" [2].

\section{Research methods}

\subsection{General design of the system}

The following is an blok diagram of a monitoring system for temperature, humidity and air quality in the room: 


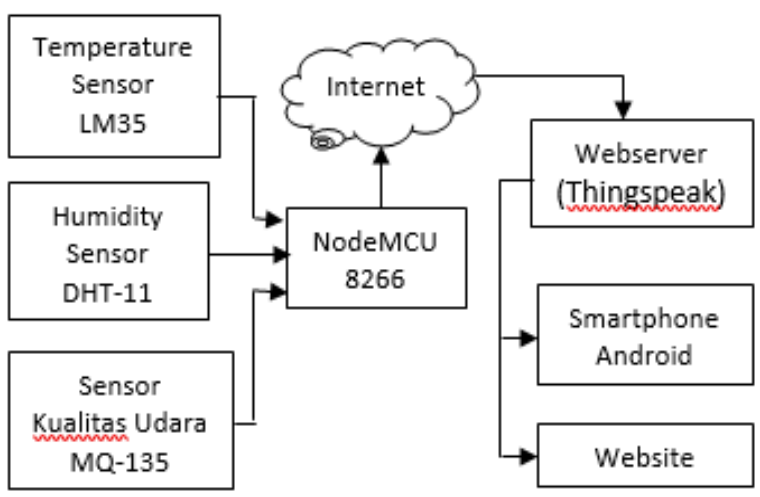

Fig -1: Blok Diagram

\subsection{System planning}

The flow of system functions can be seen in the following flowchart:

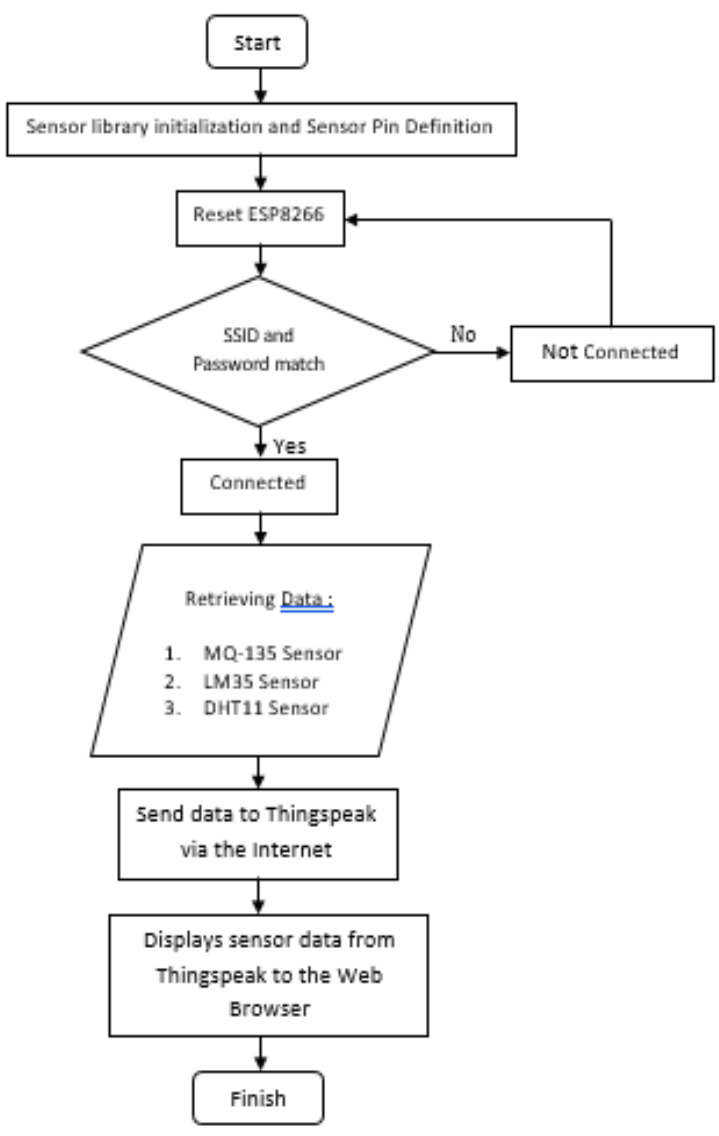

Fig -2: Flowchart System Function

\section{Results and Discussion}

The temperature, humidity and air quality monitoring system in the room to be built is a system that can monitor or see the state of the temperature, humidity and air quality in the room in real time and can be accessed using the web which is equipped with LM35 sensors, MQ-135 sensors, DHT11 sensor and NodeMCU module ESP8266. In this case the LM35 temperature sensor that functions as a temperature detector, the DHT11 sensor as a humidity sensor, and the MQ-135 sensor as an air quality detector and then the measurement results will be calibrated by the NodeMCU ESP8266 microcontroller system and the results will be sent to Thingspeak via a wifi signal using the wifi module contained in the NodeMCU module ESP8266. Then, sensor data from Thingspeak is displayed with an android smartphone and web browser.Data displayed on thingspeak in the form of graphs is the result of monitoring that has been done in realtime.

\section{Conclusions}

This research develops a monitoring system that uses the internet so that the monitoring range becomes wider. By utilizing the Internet of Things (IoT) technology using the thingspeak application integrated with the NodeMCU module ESP8266 features an LM35 temperature sensor that functions as a temperature detector, a DHT11 sensor as a humidity sensor, and an MQ-135 sensor as an air quality detector. These sensors send input signals to the NodeMCU ESP8266 module for processing. The wifi module contained in the NodeMCU ESP8266 module sends the value read by the sensor to the IoT Thingspeak platform which records logging data in graphical form. This system has the potential to be used as an indoor air quality monitoring system to raise awareness about the importance of healthy air quality.

References:

[1] Vermesan, O.,Friess, P., Furness, A., The Internet of Things 2012 New Horizons, ISBN 978-0-9553707-9-3, published in Halifax, UK, 2012, pp. 22-32.

[2] Niewolny, D., How the Internet of Things is revolutionizing healthcare, FreescaleSemiconductor, available at http://www.freescale.com/healthcare, 2013.

[3] World Health Organization., 2010, "WHO Guidelines For Indoor Air Quality: Selected Pollutant", Copenagen Denmark. [Online]. Available: https://bit.ly/217Kiny.

[4] Chiuchisan, I., Geman, O., An Approach of a Decision Support and Home Monitoring System for Patients with Neurological Disorders using Internet of Things Concepts, WSEAS TRANSACTIONS on SYSTEMS, Vol. 13, 2014.

[5] Y. Fikri, Sumardi, dan B. Setiyono., "Sistem Monitoring Kualitas Udara Berbasis Mikrokontroler ATMega 8535 dengan Komunikasi Protokol TCP/IP”. Jurnal 
Transient, Vol.2, No.3, September 2013. ISSN:2302-9927, pp. 644. [Online]. Available: https://bit.ly/2MlWNIv

[6] World Health Organization. (n.d.). Public health, environmental and social determinants of health (PHE). Retrieved 4 10, 2016, from World Health Organization: http://www.who.int/phe/air quality q\&a

[7] Harisuryo, Rafdito, Sumardi dan Setioyono, Budi. 2015. - Sistem Pengukuran Data Suhu, Kelembaban, dan Tekanan Udara Dengan Telemetri Berbasis Frekuensi Radioll. Jurnal Ilmiah Transient, Volume 4, No.3.

[8] Pasha. S. 2016.|lThingspeak Based Sensing and Monitoring System for IoT with Matlab Analysisll. Jurnal IJNTR, Volume 2, Issue 6, Page 23..

[9] ThingSpeak, The MathWorks, Inc, 2018. [Online]. Available: https://bit.ly/2JKng0Q.

[10] Q.F. Hassan., Internet of Things A to Z, 2018., Willey-IEEE Press

[11] Shifeng Fang, Li Da Xu et al., "An Integrated System for Regional Environmental Monitoring and Management Based on Internet of Things", IEEE Transactions on Industrial Informatics, Vol. 10, No.2, May 2014

[12] J. Gubbi, et al.: "Internet of Things (IoT): A vision, architectural elements, and future directions." Future generation computer systems 29.7 (2013): 1645-1660.

[13] http://www.codeproject.com/Articles/845538/A nIntroduction-to-ThingSpeak 